\title{
Sustainable Development. Environmental Management Model
}

\author{
Irina I. Rashoyan* \\ Togliatti State University, Togliatti, Samara region, Russia \\ *Corresponding author.Email: rashoyan_i@mail.ru
}

\begin{abstract}
The article provides a theoretical analysis of international experience in the implementation of the concept and the Sustainable Development Goals. The main environmental indicators of the Sustainable Development Goals in Russia are considered, which are monitored in accordance with the General Assembly United Nations Resolution "Transforming our world: the 2030 Agenda for Sustainable Development". The relationship between individual environmental indicators is shown. Studied modern methods, models and management systems that are applicable in the management of environmental protection. On the basis of the study, the concept of a model for managing environmental indicators of sustainable development in Russia is provided and criteria for assessing its effectiveness are offered.
\end{abstract}

Keywords: sustainable development, environmental performance, monitoring, analysis, management model, management system.

\section{INTRODUCTION}

The changes taking place over the past decades in all spheres of public life are accompanied by the rapid development of technological progress, social, cultural, economic and environmental processes that have a significant impact on the quality of life of the population of Russia, as well as on development of the country's regions. To achieve sustainable state development, fundamentally new approaches to formation of management systems are necessary, including in the field of environmental protection, the safety of which is one of the most important aspects of human existence. In this regard, for implementation of the state environmental policy in the Russian Federation, systematic measures are carried out, which are basically aimed at achieving a number of estimated indicators that implement the environmental component of the concept of sustainable development [1,2]. This concept has been historically and scientifically formed since the beginning of the twentieth century [2-6] and was approved by international community in 2015 in the General Assembly United Nations Resolution "Transforming our world: the 2030 Agenda for Sustainable Development" [1]. The so-called 2030 Agenda contains the main Sustainable Development Goals (SDGs) and recommends specific mechanisms to achieve them. A fairly large part of the SDGs is assessed by a number of environmental indicators. Examples of such goals might be:

- to make cities inclusive, safe, resilient and sustainable;

- to ensure sustainable consumption and production patterns.

The foregoing leads to the need for implementation of scientific research and methodological developments that will allow managing the SDG indicators to achieve the results declared by the Government and the President of the Russian Federation in various programs and state policy strategies developed and approved in accordance with the 2030 Agenda.

The purpose of the article is to develop a concept of a model for managing environmental indicators of sustainable development in Russia based on a comprehensive theoretical analysis of existing research in the field of management systems and the concept of sustainable development. tasks:

This goal can be achieved by solving the following

1. to study the international experience of implementing the concept of sustainable development. 
2. To study modern methods, models and systems of management in the public, industrial, economic and environmental spheres of activity.

3. To study environmental indicators characterizing the achievement of the Sustainable Development Goals and objectives.

4. To develop a concept of a model for managing environmental indicators of sustainable development in Russia.

\section{MATERIALS AND METHODS}

The concept of sustainable development and the mechanisms for achieving its goals is reflected in a fairly wide range of scientific and socio-political works, the authors of which are H. Bossel [2], P Hardi, T. Zdan [3], G.H. Brundtland [4], V.I. Danilov-Danilyan [5], A.D. Ursul [6] and other researchers. In general, this concept is aimed at forming a certain balance of economic, social and environmental factors, which are aimed at ensuring the life of mankind and its descendants without prejudice to the state of the environment. It is for implementation of this balance that the aforementioned Sustainable Development Goals were approved, the achievement of which is controlled by certain environmental indicators.

A large number of scientific works are recommended to solve the problems of sustainable development of Russian regions by qualitative changes in the structure of environmental policy and regular monitoring the SDG indicators [5-7 et al.].

Such a goal of sustainable development as to make cities inclusive, safe, resilient and sustainable in Russia is assessed through monitoring

- areas and number of specially protected natural areas;

- the number of cities with high and very high levels of air pollution;

- the total scope of emissions of pollutants into the air;

- the size of the population living in unfavorable environmental conditions [8]

Ensuring the sustainable consumption and production patterns is implemented in Russia by increasing:

- the number of eliminated most dangerous objects of accumulated environmental damage;

- the share of solid municipal waste sent for disposal or recycling in the total scope of solid municipal waste generated;

- the share of neutralized waste in the total scope of waste of I and II hazard classes [7].

The list of national indicators also includes other environmental criteria that characterize all the goals accepted for implementation by the international community $[1,8]$.
On the other hand, there is also a large number of works aimed at developing systems, methods and models of management [6, 9-12 et al.] which cover various aspects of social, economic and industrial activities. A fairly large number of management models can be applied in development of management systems of various levels in the field of environmental protection. In addition, it is necessary to consider the requirements of international standards (ISO 14000 series), which establish the procedure for development, monitoring and evaluation of the effectiveness of environmental management systems.

In accordance with these standards, the requirements for development of environmental management systems are based on the concept "Plan - Do - Check - Act" (PDCA). Wherein, the methods of strategic management work in almost the same way, which, in general, to achieve the SDGs, include a sequence of typical stages presented in Figure 1.

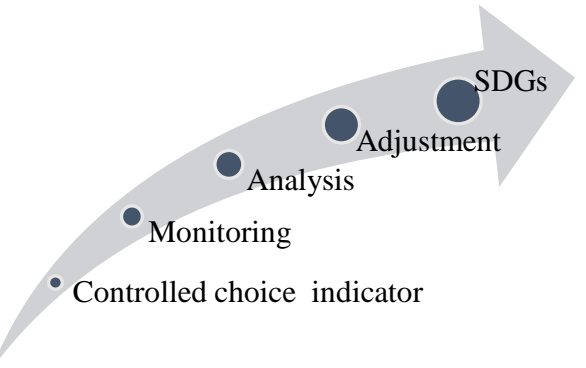

Figure 1 Strategic governance of the SDGs (compiled by the author)

At present, Russia has developed a system of global SDG indicators and is regularly monitoring and analyzing them [8], i.e. the first stages of strategic planning for the SDGs have been successfully implemented. It is worth considering in more detail the stage of adjusting the environmental indicators of the SDGs and developing the concept of a model for managing these indicators. To do this, we will consider possible options for interaction of the SDG indicators and analyze the mechanism of their relationship.

\section{RESULTS AND DISCUSSION}

As an example, consider the SDG "Make cities inclusive, safe, resilient and sustainable".

Figure 2 shows that the analyzed goal is characterized by indicators that have a mutual influence on each other. For example, an increase in the number of specially protected areas leads to an increase in their total area, which is confirmed by statistical data. In 2018, the number of specially protected areas in Russia was 218 , and in 2020 - 2208 already, which led to an increase in their area from 72,067.48 to $74,354.47$ hectares [8]. 
Ensuring openness, safety, resilience and environmental sustainability of cities and towns

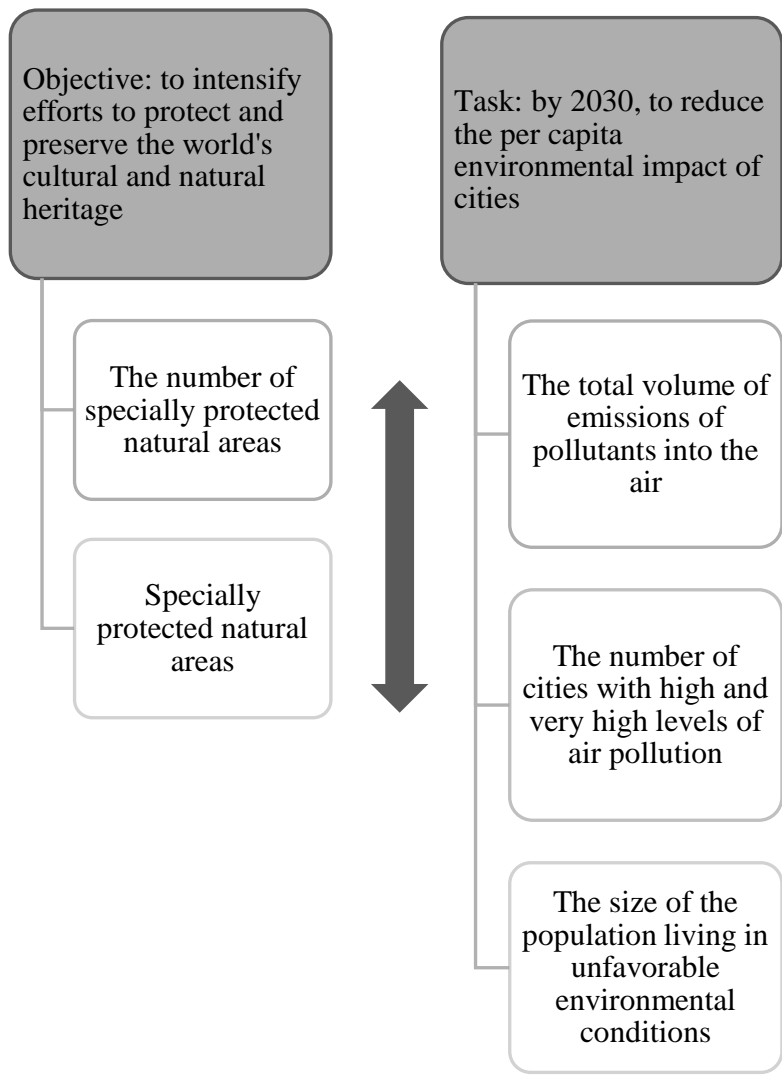

Figure 2 Interaction of target indicators to make cities inclusive, safe, resilient and sustainable (compiled by the author)

When assessing the reduction in the total volume of emissions of pollutants into the atmosphere, it can be assumed that this will reduce the number of cities with a high level of air pollution and the population living in unfavorable environmental conditions. If we look at the relevant statistics, we can also see confirmation of this assumption. In 2018, the total volume of emissions in Russia was $104.17 \%$, and in $2019-73.74 \%$. In turn, the number of the population living in unfavorable environmental conditions decreased in these years, respectively, from 13.4 to $10.6 \%$. The number of cities with a high level of air pollution was: 46 in 2018 and 40 in 2019 [8]. It shall be noted that the sample for 2018 and 2019 was made for reasons of clarity, since not all indicators have their own data for other years of statistical analysis of SDG indicators.

Therefore, we can conclude that by adjusting, if necessary, one of the environmental indicators, we are simultaneously changing the other.

It shall be noted that the most significant drawback of the SDG indicators management processes is the lack of direct information and management relationships between the responsible executive authorities. In Russia, for example, the Federal Service for Supervision of Natural Resources is responsible for control and management of the indicator "The total volume of emissions of pollutants into the air". The Federal Service for Hydrometeorology and Environmental Monitoring is responsible for indicators "Number of cities with high and very high levels of air pollution" and "Number of population living in unfavorable environmental conditions". Wherein, there is no direct access to the databases of each system for the other. In addition, the relevance of such databases varies over time. Wherein, the authority for formation and presentation of consolidated official statistical information on indicators of the SDG achievement is vested in the third system, the Federal State Statistics Service, which is not intended to perform managerial and corrective functions. Therefore, no management system (MS) can fully address one common objective for its SDGs. In this regard, the corrective control action from the control system on one of the indicators may not lead to the desired result for solving the entire problem.

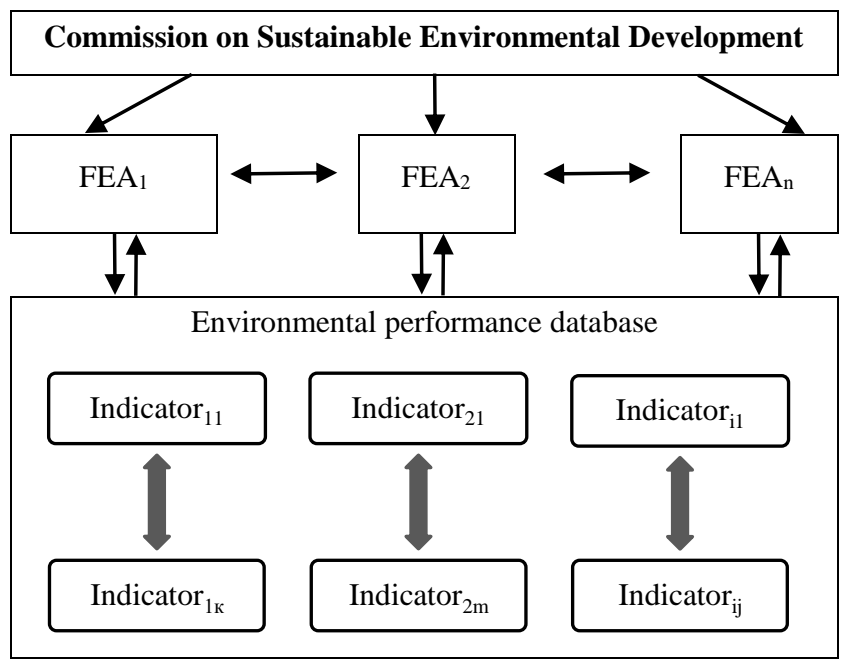

Figure 3 The concept of the model of the system of strategic management of environmental indicators of the SDGs (compiled by the author)

To solve this problem, it is offered to develop a model of the system of strategic management of environmental indicators for the SDGs (Figure 3), which can be implemented in several sequential stages.

To begin with, it is necessary to determine the structure of such a system and the relationship of the main management subsystems, which shall include the main responsible federal executive bodies (federal executive authorities) in accordance with the list of national SDG indicators approved in Russia. Within the framework of this list, it is necessary to highlight the main environmental indicators and identify their possible functional relationship and quantitative characteristics. If possible, it is worth establishing a 
correlation between them, which will help to identify the ways and mechanisms for managing indicators. After that, it is required to draw up a list of federal executive authorities that are responsible for monitoring these indicators, and which will compose the management subsystems necessary for our model.

Next, it is necessary to build structural models of these subsystems and models of the processes of their interaction, as well as to select a single body for their control within the framework of the projected MS. It is offered to arrange a Commission on Sustainable Environmental Development as a single governing body of the MS (Figure 3), which may include representatives of all federal executive authorities participating in the work of the planned system. Wherein, the Federal State Statistics Service continues to perform the functions of the unified database. Therefore, the offered MS will be built on the basis of the basic properties of hierarchy, interdependence of elements and continuity of relationships that characterize management activities. The hierarchy of such a system indicates the subordination of various levels of management. The interdependence of the MS elements will make it possible to more effectively use the possibility of adjusting and adapting the levels and subsystems of control when changing certain environmental indicators. The continuity of the system links will allow for consistency in execution of management objectives to achieve the SDGs.

The next stage in the design of the MS model is the formulation of regulations for the functioning of the system. For example, for implementation of the activities of the offered Commission, the following tasks can be distinguished:

1. Ensuring the coordinated activities of federal executive authorities and their subordinate organizations to develop the main directions of state environmental policy.

2. Development of the main strategic directions for improving the state environmental policy.

3. Analysis of offers for implementation of the state environmental policy within the competence of each federal executive authority.

4. Arrangement of continuous monitoring of the environmental indicators of the SDGs and formation of the single database.

5. Collection and analysis of information from the single database of environmental indicators.

6. Development of corrective measures for environmental protection based on the analysis of environmental indicators to achieve the Sustainable Development Goals.

7. Determination of the amount of funding for activities aimed at achieving the Sustainable Development Goals.

8. Coordination of the activities of management subsystems (federal executive authorities and subordinate organizations) in implementation of corrective measures for environmental protection in the framework of achieving the set SDGs.

At the final stage, an expert assessment of the system's operation follows, and, if necessary, a verification calculation for its stability, adjustment and optimization of control processes is carried out. Wherein, the MS designed as a result shall provide each federal executive authority subsystem with the ability to use and manage a certain set of indicators that are interconnected and aimed at solving one SDG task. The coordination of federal executive authorities' activities within the framework of a single task will be carried out by a common governing body represented by the Commission on Sustainable Environmental Development.

\section{CONCLUSION}

The MS model presented herein is conceptual in nature, since each stage of its design described above requires further detailed study. Accordingly, an expert assessment of the system's performance, as mentioned above, is possible only at the final stage of its design. Nevertheless, based on the requirements for environmental management systems (ISO 14031: 2021), a number of criteria can already be offered for the subsequent assessment of the effectiveness of the developed management system:

- identification of the functional and/or correlation relationship between the existing environmental indicators of the SDGs;

- the ability to identify the root causes affecting the SDG indicator;

- the ability to develop corrective and control actions in management subsystems (federal executive authorities and subordinate organizations);

- positive changes in the SDG indicators based on the results of corrective actions;

- economic costs versus achieved changes in the SDG indicators (cost-effectiveness);

- achievement of the planned Sustainable Development Goals.

As a result of implementation of the offered model, it is expected that the output will be optimal strategies for managing the environmental indicators of the SDGs. In addition, a generally similar model can be developed and used to improve the efficiency of nature management and environmental protection at various levels of government.

\section{REFERENCES}

[1] Transforming our world: the 2030 Agenda for Sustainable Development: Resolution adopted by the General Assembly United Nations on 25 
September

2015. https://www.un.org/ga/search/view_doc.asp?symbo $\mathrm{l}=\mathrm{A} / \mathrm{RES} / 70 / 1 \&$ Lang $=\mathrm{E}$.

[2] H. Bossel, Indicators for Sustainable Development: Theory, Method, Applications. A Report to the Balaton Group. IISD, Winnipeg, Manitoba, 1999.

[3] P Hardi, T. Zdan, Assessing sustainable development: Principles in practice. IISD, Winnipeg, 1997.

[4] Report of the World Commission on Environment and Development: Our Common Future, in: A/42/427 - Development and International Cooperation: $\quad$ Environment, 1987. https://sustainabledevelopment.un.org/content/docu ments/5987our-common-future.pdf.

[5] V.I. Danilov-Danilian, Sustainable development (theoretical and methodological analysis), in: Economics and Mathematical Methods, CEMI RAS, Moscow, 39(2) (2003) pp. 123-135.

[6] A.D. Ursul, The concept modeling of the stable development, in: Ecology of urban areas, Publishing House «Kamerton», Moscow, 2 (2006) pp. 22-34.

[7] E. Polyakova, L. Gorina, Environmental security and sustainable development of large urban centres, in: E3S Web of Conferences, "1st Conference on Traditional and Renewable Energy Sources: Perspectives and Paradigms for the 21st Century, TRESP 2021", 2021, pp. 01003.

[8] Sustainable Development Goals in the Russian Federation. Brief statistical collection. Rosstat, Moscow, 2020.

[9] A.T. Omarova, B.K. Jazykbayeva, Y.D. Orynbassarova, M.F. Grelo, Model of environmental governance in Kazakhstan, in: Bulletin of Karaganda University. Economy Series, 91(3) (2018) pp. 88-96.

[10] Shuang Qiao, Pan Wang, Yang Bai, Global Clean Energy Governance Mechanism Research - Based on power model, in: IOP Conf. Ser.: Earth Environ., 565 (2020). DOI: https://doi.org/10.1088/1755-1315/565/1/012009.

[11] A. Dale, K. Vella, R.L. Pressey, J. Brodie, H. Yorkston, R. Potts, A method for risk analysis across governance systems: a Great Barrier Reef case study, in: Environ. Res. Lett., 8 (2013). DOI: https://doi.org/10.1088/1748-9326/8/1/015037

[12] V.A. Filimonov, L. Gorina, Development of an occupational safety management system based on the process approach, in: Journal of Mining Institute, Saint Petersburg, 235 (2019) pp. 113-122. 